\title{
Advances in understanding the genetics of pig behaviour
}

Lotta Rydhmer, Swedish University of Agricultural Sciences, Sweden

\section{bjourleigh dodds \\ O SCIENCE PUBIISHING}




\section{Advances in understanding the genetics of pig behaviour}

Lotta Rydhmer, Swedish University of Agricultural Sciences, Sweden

1 Introduction

2 Maternal behaviour

3 Feeding behaviour and the consequences of selection for feed efficiency

4 Tail biting

5 Aggressive behaviour between pigs

6 Direct and social effects on growth rate and reproduction traits

7 Characteristics of pigs with high social breeding values for growth rate

8 Conclusion and future trends

9 Where to look for further information

10 Personal communications

11 References

\section{Introduction}

The pig is an explorative animal with a large ability to adapt to different environments. Its large litters (no other animal as large as the pig gives birth to so many young) demand a maternal behaviour that is very different from other livestock. A successful maternal behaviour is crucial for the efficiency of piglet production. Pigs are generally kept in groups and their social behaviour has an impact on animal welfare in positive and negative ways. Social interactions influence growth of young pigs and reproduction of sows. Common pig production routines, like tail docking and keeping sows in crates, are strongly connected to pigs' behaviour and these routines are highly problematic from an animal welfare perspective.

Apart from the joy of research in general and animal science in special, there are several reasons to study and learn more about the genetics of pig behaviour:

- Pig behaviours influence animal welfare;

- Pig behaviours influence work satisfaction of care takers; 
- Pig behaviours influence production profit; and

- Some pig behaviours (e.g. tail biting) or their interventions (e.g. tail docking) influence consumers' acceptance of pig production.

There seems to be a genetic variation in most behavioural traits that have been studied in pigs, and many examples will be given in this chapter. The chapter starts with a review of the genetic background of various behavioural traits, with references to molecular genetic studies as well as quantitative genetic studies. The group model with its direct and social genetic effects is described and consequences of selection for social breeding values are presented. Some future perspectives on methods and breeding goals, and the room for selection for changed behaviours, are discussed.

\section{Maternal behaviour}

One way to express the goal for piglet production is 'a high number of healthy piglets with a low variation around the target weaning weight'. The level of this target weight depends on management system and factors like weaning age, nutrition value of piglet feed and use of nurse sows. Although several genetic studies of maternal behaviour are found in the literature, maternal behaviour traits are usually not included as selection traits in pig breeding programs. Instead, the selection traits are piglet survival and piglet growth, traits more directly reflecting the goal and also more easy to record than behavioural traits. Nevertheless, we can achieve a better understanding of opportunities and limitations of piglet production from genetic studies of nest building, savaging, crushing and nursing.

Sows obviously need straw or other construction material to build a nest, but an increased activity with a typical behavioural pattern before farrowing can be seen also in sows not provided any building material. Sows actively engaged in nest building before farrowing calms down when the nest is built and thereafter move less during farrowing, thus reducing the risk of crushing new-born piglets and increasing the possibility for all piglets to achieve colostrum (Ocepek et al., 2017). Accordingly, Ocepek and Andersen (2018) found that nest building activity is associated with a lower proportion of starved piglets and overlaid piglets. Nest building is related to oxytocin and preliminary results of Rydhmer and Jonas (2016) show an association between the oxytocin synthesis gene and nest building behaviour. An association between the oxytocin gene and stillborn piglets, but not between the gene and survival of live born piglets, was found in the same project (Jonas and Rydhmer, 2018).

Savaging of new-born piglets (infanticide) is associated with low plasma oxytocin levels at farrowing (Gilbert, 2001). Around $5-11 \%$ of primiparous sows savage their piglets (Chen et al., 2008; Gäde et al., 2008) and the repeatability is 
around 0.4 (Gäde et al., 2008). An ongoing threshold selection against savaging at herd level seems plausible; farmers avoid selecting gilts for replacement born by savaging sows. Old studies reported high heritability estimates for savaging, but Gäde et al. (2008) estimated the heritability at 0.02. Several QTLs for savaging have been found (Chen et al., 2009b) and for some of them genes involved in anxiety are located in homolog chromosome regions in humans (Daigle, 2018). This is an example of studies where pigs are used as model for humans in studies of psychiatric disorders (Daigle, 2018).

Bauer (2019) recently presented a doctoral thesis on genetic components of savaging. He found associations between savaging and genes involved in the regulation of dopamine, vasopressin and oxytocin levels, and also genes involved with mitochondria and energy production "suggesting that alteration of the genome impacting on the way the cells produce energy could have a behavioural impact" (Bauer, 2019). Savaging sows show a more active behaviour and they are more responsive to piglets (Jarvis et al., 2004; Chen et al., 2008). Outdoor raised sows selected for the maternal effect on piglet survival had a higher frequency of savaging (compared to a control line) when they farrowed indoors (Baxter et al., 2011). This could be interpreted as savaging being the outcome of a low ability to cope with a confined environment under high pressure. Assuming that the pressure on the sow increases with increasing litter size, this is however contradicted by a negative genetic correlation between litter size (total born) and savaging ( $\left.r_{g}=-0.34\right)$ estimated by Gäde et al. (2008).

Farmers' judgement of sow behaviour was studied by Stratz et al., 2016. A good farrowing behaviour included remaining in lying position during farrowing, not snapping or biting piglets and having a rapid farrowing. The heritability for this farrowing behaviour was estimated at 0.07 . Farrowing behaviour was correlated to piglet weight at weaning $\left(r_{g}=0.52\right)$ and to piglet vitality $\left(r_{g}=0.32\right)$. It has previously been reported that unsavaged piglets are heavier at birth than savaged piglets (Grandinson et al., 2002) and it can be hypothesised that the genotype of the piglet influences the risk of being savaged. This would motivate the use of a genetic model including two genetic effects - a direct (piglet) and a maternal (sow) - in the model when analysing savaging. No such genetic analysis has been found in the literature.

When nucleus farmers recorded how often the sow showed careless behaviour among the piglets, the heritability of carefulness was estimated at 0.1-0.2 in two different breeds (Vangen et al., 2005). Hellbrügge et al. (2007, 2008) studied maternal behaviour on thousand German Landrace sows in a nucleus herd. The main piglet mortality cause was crushing by the sow. The sow's reaction to a recorded distress call was heritable $\left(h^{2}=0.13\right)$. A stronger reaction was genetically correlated with higher piglet survival, but the correlation was low and not significant. The sow's reaction to an unknown sound (music) was also heritable and showed a higher correlation 
with piglet survival $\left(r_{g}=0.26, S E \pm 0.18\right)$ and with number of piglets crushed during the first days $\left(r_{g}=-0.28, S E \pm 0.19\right)$. The sow's reaction when separated from the piglets three weeks after farrowing had a low heritability but was highly correlated with the reaction to an unknown sound ( $\left.r_{g}=0.89, \mathrm{SE} \pm 0.35\right)$. The reaction when separated from the piglets was also correlated with piglet survival $\left(r_{g}=0.44, S E \pm 0.31\right)$. Standard errors are given for these estimates to illustrate that although behavioural records from thousands of sows takes a lot of time to collect, it is hardly enough to estimate genetic parameters for these complex traits.

According to Stratz et al. (2016), a good nursing behaviour includes not lying on the udder, feeding piglets until satiation and having a well-developed udder with functional teats. The heritability for assessed nursing behaviour was estimated at 0.10 and the nursing behaviour was genetically correlated with piglet weight at weaning $\left(r_{g}=0.86\right)$.

Selection for increased litter sizes increase the demands on the sow; it should avoid crushing any piglet and provide enough milk to all piglets. For animal welfare reasons we want to get rid of the farrowing crates. Genetic predisposition for larger litters in combination with loose-housing are motives for selection for maternal abilities. As described above, there are several heritable maternal behaviour-traits, but recording behaviour is time-consuming and thus expensive. Selection for high piglet survival and piglet growth rate, using both direct (piglet) and maternal (sow) breeding values, may be a better alternative than introducing behavioural tests in the breeding program of dam lines.

\section{Feeding behaviour and the consequences of selection for feed efficiency}

Being an omnivore, the pig is an explorative animal with a high capacity to adapt to a wide range of feeds and environments (discussed by Brunberg et al., 2016). Pigs show a large variation in feeding behaviour as a consequence of the management system, such as ad libitum feeding in feeders or restricted group feeding in troughs once per day, and there is also a genetic variation (Rohrer et al., 2013). Automatic feeders are often used to record individual feed intake of growing pigs. This equipment also provides large amounts of feeding behaviour data that until now have not been of much use for selection. Kavlak and Uimari (2019) analysed data from more than 3000 pigs fed with electronic feeders at a test station. The feeding behaviour traits were number of visits per day, time spent in feeding per day, time spent feeding per visit and feed intake per visit. Heritabilities of these traits were estimated at 0.17-0.47, but none of them were genetically correlated to any production trait. The authors thus concluded that there is no reason to include feeding behaviour in the genetic evaluation. 
Several quantitative trait loci (QTL) for feeding behaviour have been found. Reyer et al. (2017) found QTLs for daily feeder occupation time and number of daily feeder visits. Some candidate genes were identified; one of them (MC4R at chromosome 1) with effect on energy homeostasis influencing feed intake. Although both daily feed intake and nutrient needs change with age, strong genetic correlations have been found between feeding behaviour traits recorded at different ages (Kavlak and Uimari, 2019). In a genome wide association study, the QTLs identified for feeding behaviour recorded during two age periods on growing pigs were, however, not the same (Guo et al., 2015). When 338 Duroc boars with records on daily feed intake, number and duration of visits per day and feed intake per visit were genotyped; six SNPs associated with feeding behaviour were located in genomic regions where QTLs for feeding behaviour have been found earlier (Ding et al., 2017). Five candidate genes with biochemical and physiological roles relevant for feeding behaviour were recognized close to these markers. Several of the candidate genes were involved in the development of the hypothalamus; on organ important for the regulation of hunger. Future functional genomic studies may reveal the genetic regulation of feeding behaviour and feed intake.

The main motive for genetic studies of feeding behaviours seems to be their relation to feed efficiency; an important goal trait in most pig breeding programs. According to a French selection experiment lasting for nine generations, selection for more efficient pigs (low residual feed intake (RFI)) results in pigs with lower physical activity during both day and night, as compared to pigs selected for high RFI (Meunier-Salaün et al., 2014). The low RFI line also seemed to be less affected by tail biting, which may be a consequence of the lower activity level. When comparing the high and low RFI lines, no behavioural difference was found in a novel object test (MeunierSalaün et al., 2014). Colpoys et al. (2014) also compared the behaviour of pigs selected for high or low RFI and concluded that low RFI pigs were more calm in the home pen as well as in novel object and human approach tests, thus less reactive to novelty.

Changes (or lack of changes) in feeding behaviour can also be used as an indicator of robustness, for example, the ability to cope with heat (Cross et al., 2018). Furthermore, feeding behaviour can be used as an indicator of behavioural traits difficult to record, such as risk of becoming a victim of tail biting (Wallenbeck and Keeling, 2013). Rohrer et al. (2013) found that pigs with a reactive coping style, recorded in a backtest, tended to eat fewer but longer meals per day. Data from feeding stations are 'for free', and with increased knowledge in bioinformatics, the use of the large amounts of data from feeding stations will maybe increase in future herd monitoring and breeding programs. 


\section{Tail biting}

Tail biting is a multi-factorial problem, with both environmental and genetic causes. Breuer et al. (2005) found a positive genetic correlation between tail biting and lean tissue growth rate and a negative genetic correlation between tail biting and backfat thickness. Brunberg et al. (2013b) reported a genetic association between tail biting and fatness; biters and victims had a different expression of the gene PDK4 compared to pigs not involved in tail biting. The PDK4 gene has an impact on fat content in pigs (Lan et al., 2009). Selection for lean pigs may thus increase the risk of tail biting. Using metabolites from pigs as phenotypes in a genome-wide association study, Dervishi et al. (2019) showed that pigs predisposed to be bitten may have an impaired lipolysis process.

There are several challenges related to genetic analyses of tail biting and - although highly relevant for pig welfare - genetic studies of tail biting are scarce. If a pig becomes a tail biter or a victim of tail biting depends both on the pig itself and on its group mates (discussed by Brunberg et al., 2016). Data from several thousand pigs may be necessary to get accurate genetic estimates. Tail biting behaviours are often recorded as binary traits, which increases the need for large data sets even more. Bitten tails can be recorded by repeated visual monitoring, but the frequency is often low which puts high demands on the statistical model used for genetic analysis. To identify biting pigs by direct observations or video recording is very time-consuming. Furthermore, the expression of tail biting differs over time as a pig can change from being a nonbiter to being a biter (Ursinus et al., 2014).

Breuer et al. (2005) estimated the heritability of performing tail biting in Landrace pigs at 0.05. More recently, Canario and Flatres-Grall (2018) estimated the heritability of being a victim at 0.06 in Tai Zumu pigs. The genetic correlation between being a biter and being a victim is not known. Brunberg et al. (2013a) found some SNPs that had the same associations to both being a biter and being a victim, but these SNPs were not associated with being a neutral pig. Neutral pigs are pigs neither being biters nor victims in pens where tail biting is ongoing. Wilson et al. (2012) found that some SNPs are associated with being neutral whereas other SNPs are associated with being a biter or a victim. A study on gene expression in the brain also suggested that biters and victims have more in common than neutral pigs (Brunberg et al., 2013b).

Neutral pigs (in pens with tail biting) performed less pig-directed behaviours, such as belly nosing and tail in mouth, compared to pigs in pens without tail biting (Brunberg et al., 2013a), and 100 transcripts were differently expressed between those two types of pigs. Several of the transcripts were also differently expressed in neutral pigs as compared to both biters and victims (Brunberg et al., 2013b). This suggests that neutral pigs' gene expression is not a consequence of not being involved in tail biting, but rather a cause for 
not being involved. Are neutral pigs the pigs that should be selected? We do, however, not know what would happen if all pigs in a pen were genetically predisposed to be neutral.

Camerlink et al. (2015) compared the behaviour of two groups of pigs with different social breeding values for growth rate. The pigs were studied in two environments, in barren, standard pens and in pens with lots of straw. As expected, less tail biting was performed in pens with straw. Pigs with high social breeding values in enriched pens showed least biting behaviour and pigs with low social breeding values in barren pens showed most biting behaviour.

\section{Aggressive behaviour between pigs}

In todays' pig production, most pigs meet unfamiliar pigs at several occasions, for example, at weaning, when moved to the finishing stable and at the abattoir. Except for a short period during the first weeks of life, such mixing of pigs leads to fighting. In addition to the intensive fighting just after mixing when a rank order is established, aggressive behaviour is also seen in stable groups of familiar pigs.

In general terms, the neuropeptide vasopressin facilitates aggression whereas serotonin inhibits aggression. Terenina et al. (2012) identified markers in young pigs indicating that aggressive behaviour is associated with genes related to vasopressin (number of attacks and number of fights won) and serotonin (number of attacks and number of fights involved in). Four markers for the dopamine receptor were also associated with aggressive behaviour (number of fights involved in, number of attacks, number of fights won). Pigs can be classified according to two coping styles: the proactive style with increased aggressiveness and the reactive style with reduced aggressiveness. A pig's reaction when placed on its back in the so-called backtest is used to test coping style. A proactive pig shows more resistance and struggling in the backtest. The result of the backtest is heritable in pigs (Rohrer et al., 2013). A proactive coping style is related to low activity in the hypothalamicpituitary-adrenal (HPA) axis and low parasympathetic activity accompanied by high levels of sympathetic and testosterone activity. A reactive coping style is related to elevated HPA axis and parasympathetic activity and low levels of sympathetic activation and testosterone levels (Koolhaas and Boer, 2008). Amygdala and hippocampus are involved in the regulation of the HPA axis. Ponsuksili et al. (2015) identified several markers on chromosome 12 associated with pigs' reaction in a backtest. In a recent study, Ponsuksili and co-authors also demonstrated an interplay between haplotypes associated with coping behaviour in this region and transcriptome profiles in amygdala and hippocampus (Gley et al., 2019). Candidate genes were discovered which relate to the dopaminergic neurotransmitter system. Differently expressed 
genes also indicated immunological differences between animals with different coping styles (Gley et al., 2019). Large-scale recording of young pigs' coping style with backtest seems feasible, and it is tempting to use the test result as an indicator trait in breeding for reduced aggressive behaviour. The backtest, however, seems to tell more about the pigs' reaction to fearful situations than to the pigs' predisposition for showing aggressive behaviour (Zebunke et al., 2017).

As the development of stronger animal welfare laws deliberate sows from gestation stalls in many countries, fighting of sows becomes an issue. Eighteen percent of the pregnant sows in a nucleus herd showed aggressive behaviour at mixing, in a study by Helbrügge et al. (2007). The heritability of this binary trait was estimated at 0.32 with a threshold model. Appel et al. (2013) studied aggressive behaviour of gilts at mixing in two herds. The levels of aggression differed between herds but no genotype by environment interactions were found. The heritabilities were estimated at 0.20 for aggressive attack and 0.16 for reciprocal fighting. These traits were highly correlated $\left(r_{g}=0.95\right)$ and recording one of them would be enough for genetic evaluation. The authors conclude, "Selection for reduced aggression in group-housed animals seems to be feasible and desirable to improve the welfare of the animals" (Appel et al., 2013). In a later study, Appel et al. (2016) followed the gilts until they became sows showing maternal behaviour. The correlations between sows' response when separated from piglets one day after farrowing and aggressive behaviour (attack and fighting) were negative, that is, sows genetically predisposed to be less aggressive were also genetically predisposed to show a strong response in the separation test. This is not necessarily favourable, since the results also indicated that a strong response in separation test is genetically correlated to an increased risk of becoming a 'problem sow'. Usability (need for additional labour input) was recorded by care takers ten days after farrowing on a 3-point scale from 'no additional effort' to 'problem sow'. According to the genetic correlation, this usability was almost the same trait as sows' ability to raise a large litter of homogenous piglets according to care taker's judgement day 10 (more effort needed - more heterogenous litter, $r_{g}=0.91$ ). Gilts genetically predisposed to be less aggressive were genetically predisposed to rear large, homogenous litters. The authors stress that large-scale recording of aggressive behaviour is feasible; less than two minutes per gilt was needed in their study (Appel et al., 2016). Sows' aggressive behaviour at mixing is recorded in nucleus herds by a German breeding organisation and included in the genetic evaluation of their dam line (Hubert Henne, personal communication).

Stukenborg et al. (2012) recorded the start and finish times of each aggressive interaction, the identity of the aggressor and the receiver, and whether they were the winner or loser of the fight during 48 hours, at three occasions (weaners, growing pigs and gilts). The highest heritability was estimated for the 
number of won fights for growing pigs $\left(h^{2}=0.37\right)$. For piglets at weaning, the highest heritability was estimated for time spent in initiated fights $\left(h^{2}=0.20\right)$. The genetic correlations between aggressive behaviour at weaning and later in life, when being a growing pig or a gilt, were generally low (Stukenborg et al., 2012). Within occasion, the genetic correlation between number of initiated and won fights was stronger than the correlation between number of initiated and lost fights. This relationship - pigs initiating many fights win most of the fights - was later confirmed by Sheffler et al. (2016). Performing aggressive behaviour is a more heritable trait than being a victim (Løvendahl et al., 2005). Likewise, the heritability of number of skin lesions on anterior part of the body is higher than the heritability of skin lesions on the posterior part (Wurtz et al., 2017). Based on all these studies, selection against performing aggressive behaviour at mixing seems feasible, but recording aggressive behaviour comes with additional costs for the breeding organisation. The genetic correlation between aggressive behaviour of growing pigs and aggressive behaviour of sows needs to be further investigated.

Skin lesions have been used as an indicator trait for aggressive behaviour (Turner et al., 2009). The number of lesions is a heritable trait both after mixing and in stable groups (Desire et al., 2015). The genetic correlations between number of fresh lesions after mixing at ten weeks of age and five weeks later (in the same groups) were moderate for lesions on the posterior body $\left(r_{\mathrm{g}}=\right.$ $0.46)$ and high for lesions on the anterior body $\left(r_{g}=0.76\right)$. The position of the lesions is crucial for their use as indicators of aggressive behaviour. Posterior lesions are genetically correlated to receiving aggression and anterior lesions to reciprocal fighting and delivering aggression in nonreciprocal interactions (Turner et al., 2009). According to Desire et al. (2016), skin lesions in the front recorded shortly after mixing can be used in selection against both reciprocal and nonreciprocal aggression after mixing. Such selection may not only increase welfare, but also increase loin muscle area without negative effects on growth rate (Wurtz et al., 2017).

\section{Direct and social effects on growth rate and reproduction traits}

A pig's performance is governed by its genotype and influenced by the environment. Often the most important elements of this environment are the other pigs in the pen and their influence is in turn governed by their genotypes. The group mates may be genetically predisposed to influence other pigs in a favourable or an unfavourable way. In the group model (also called the social model) there are two different genetic effects; the direct effect which explains the pigs' own capacity to perform, and the social (indirect) effect which explains the effect of group members on a pig's performance; that is, the genetic ability 
to influence other pigs in the group (Muir, 2005; Bijma et al., 2007). In pigs, the group model including these two genetic effects has mostly been used for analysing growth rate.

The social genetic effect on growth rate is most likely a consequence of 'good' or 'bad' behaviour, but the group model does not per se describe any behaviours. It merely describes an outcome of social interactions in a group and this outcome is the growth rate of all pigs in that group. If the pigs compete over a limited resource, for example restricted feeding, the genetic correlation between the direct and the social effect will be negative and unfavourable. Such a negative correlation was found by Muir (2005) in quails. If the correlation is negative, selection for pigs with high direct breeding values will have a negative effect on the growth rate of the whole group. A zero correlation between the direct and social effects means that selection for the direct effect on growth rate will not have a negative influence on the growth rate of the group members. Even so, selection for growth rate based on a group model including both the direct and social genetic effects utilize the full genetic variation and will result in a faster genetic progress than selecting for growth rate with a model only including a direct genetic effect of the animal (Rodenburg et al., 2010). In a competitive environment where the genetic correlation between the direct and the social effect is negative, the motive for using the group model in the genetic evaluation is even stronger.

The group model assumes that an animal has the same social genetic effect on all other group members although it is known from behavioural studies that the number of social interactions differ between dyads in the group (Løvendahl et al., 2005). The number of potential interactions of course increases with group size and an effect of a variable group size can be handled by including a dilution factor in the genetic model (Bijma, 2010a). Very large data sets are needed to get accurate estimates of the genetic parameters and ideally, the groups should consist of pigs from two litters when applying the group model (Bijma, 2010b) but this is difficult to achieve in practice. Another difficulty when analysing growth rate with the social model is that some pigs are lost due to injuries or even death and they will not get records on growth rate (as discussed by Bunter et al., 2015). Assuming that the group model partly describes a consequence of receiving aggressive interactions, these pigs could have been the most informative ones if they were not lost. It would be good to include information on their growth rate until the day they were taken out of the group.

The group model has been used to analyse growth rate of pigs by for example, Bergsma et al. (2008), Chen et al. (2009a), Canario et al. (2012) and others. No behavioural records are needed in such studies, but we often assume that social genetic effects are related to competition and aggressive behaviour (Rodenburg et al., 2010). We will come back to behavioural differences between pigs with high and low social breeding values. 
Nielsen et al. (2018) state that the group model "has not yet been shown to consistently improve predictive ability [of breeding values] compared to the classical animal model" and hypothesize that one reason for this is that direct and social genetic effects differ between males and females. They analysed growth data (30-94 kg) from 80000 pigs kept in sex sorted groups with an average group size of around 11 pigs. The pigs were fed ad libitum. No pigs were castrated. Growth rate in males and females were handled as different traits in a bivariate analysis. Significant social genetic variances were found for both sexes and the total heritability estimates (including direct and social variance) were 0.32 for males and 0.27 for females. The genetic correlation between the social genetic effects of males and females was rather low (rg $=0.30$ ), indicating that growth rate is not the same trait in both sexes. The group model improved the predictive ability (i.e. the correlation between breeding values and phenotype values of growth rate) for both sexes. The genetic correlation between the direct and the social effect differed between sexes (-0.04 for males and -0.22 for females), indicating competition among females but not males (Nielsen et al., 2018). The authors admit that this is surprising, since entire males generally show more aggressive behaviour than females.

Group-housed sows in general have better welfare than sows kept in individual stalls and consequently individual stalls for pregnant sows are forbidden in the EU. For some sows the welfare in these group pens is, however, low due to aggressive interactions and competition for resources. The hypothesis of Bunter et al. (2015) was that some sows may be better adapted to group housing. They used the group model to analyse reproductive data from around 8000 sows that were group housed during gestation. The sows were mixed after pregnancy test and stayed in the groups until a few days before farrowing. The pens were designed for a maximum number of 4 , 8 or 10 sows (all pens with $1.5 \mathrm{~m}^{2}$ per animal) and a majority of the groups included the maximum number of animals. Total number of piglets born and number born alive were analysed with different versions of the group model. The direct heritabilities for litter sizes were estimated at 0.11-0.12. The social heritability estimates were much lower (0.001-0.002) and the total heritabilities were estimated at $0.14-0.16$. Applying dilution factors to handle the range of group size did not improve the fit of the model. The authors propose that dilution factors are relevant only when resources are fixed per group and not per individual as in this study. The model fit was however much improved by including an effect of number of sows in relation to the maximum number for the given pen size, i.e. a combination of number of sows to interact with and area per sow. When this effect was included in the model, the correlations between the direct and the social genetic effects were close to zero for both litter sizes. Without this number-area-effect, the correlations between the direct and the social effect were estimated at 0.3-0.4 (Bunter et al., 2015). This difference 
between models raises questions about previous positive correlation estimates from the group model. It should, however, be remembered that growth rate, the trait typically analysed with the group model, may be directly influenced by other pigs competing more or less over feed resources as both the direct and the social genetic effects may partly reflect feed intake. For litter size, the direct genetic effect reflects ovulation rate and embryo survival whereas the social genetic effect must reflect an indirect genetic effect of, for example, aggressive behaviour causing stress (and thus embryonic loss), as discussed by Bunter et al. (2015).

\section{Characteristics of pigs with high social breeding values for growth rate}

Different behaviours have been compared for pigs with high and low social breeding values for growth rate. Pigs with high social breeding values seem to be calmer (more time lying down) in stable groups (Canario et al., 2012). In a small study by Hong et al. (2018a), pigs' behaviour was recorded with scan sampling during day time. One day after mixing and one month after mixing, pigs with high social breeding values spent less time on aggressive behaviour and more time on feeding than pigs with low social breeding values. They were also more often feeding together with other pigs. Two weeks after mixing, the results were less clear.

The aggressive behaviour of pigs with high social breeding values for growth rate is complicated to describe and interpret. Pigs with a high social breeding value tend to show more aggressive behaviour at mixing, but less aggressive behaviour later on (in stable groups) as compared to pigs with low social breeding values (Rodenburg et al., 2010; Canario et al. 2012). This has been interpreted as a higher ability of pigs with high social breeding values to quickly form dominance relationships in a new group. The study by Canario et al. (2012) indicates that the behaviour of pigs with high social breeding values differs with the level of competition in the group. When the environment is competitive (negative correlation between the direct and the social genetic effect), pigs with high social breeding values initiate less fights and lose more fights after mixing than pigs with low social breeding values. When there is a positive correlation, they initiate and win more fights after mixing, thereby actively participating in a quick establishment of the social hierarchy within the group.

Camerlink (2014) and Reimert (2014) both studied pigs from a onegeneration selection experiment. Half of the pigs were offspring of sows and boars with extremely low social breeding values for growth rate $(25-110 \mathrm{~kg})$ and the other half were offspring from sows and boars with extremely high social breeding values. The direct breeding value for growth rate was equal 
between both the groups. The offspring (480 pigs) were reared in five batches and their behaviour was tested at several occasions. Half of them were kept in barren pens and half of them in enriched pens.

Before weaning, no difference between groups was seen in a backtest (Reimert etal., 2013). When tested in a novel object test and in a human approach test, high-social pigs were quicker to touch the object and more frequently present near humans (Reimert et al., 2013). When tested in the home pen a few weeks after weaning, high-social pigs were faster to touch a novel object but no difference was seen in a human approach test (Reimert et al., 2014a). The pigs were tested again at 13 weeks of age, this time in a novel environment. Fourteen different behaviours were recorded and the only significant difference was that high-social pigs showed less locomotion after the introduction of the novel object (Reimert et al., 2014a). No difference between groups was found in salivary cortisol measured after this test. In summary, the authors conclude that high-social pigs "might be less fearful" than low-social pigs.

Camerlink et al. (2015) found that high-social pigs showed less ear biting and chew less on jute sacks (more chewing is an indicator of pigs being predisposed to tail biting). The behavioural differences between pigs kept in barren and enriched pens were generally larger than the differences between high- and low-social pigs and no genotype by environment interactions were found. Genetic and environmental improvements are thus additive which increases the opportunities to work for improved welfare. There was no difference between high-social and low-social pigs in the number of skin lesions or number of reciprocal fights in stable groups or in confrontation with unfamiliar pigs in a re-grouping test at 9 weeks of age (Camerlink et al., 2013). Pigs from the high-social group did, however, perform less non-reciprocal fighting and showed less aggressive behaviour when meeting familiar group members after $24 \mathrm{~h}$ of separation during the re-grouping test (Camerlink et al., 2013). A re-grouping test is a stressful event and Reimert et al. (2014b) analysed several blood variables before and after the re-grouping test. The results indicated that high-social pigs were less affected by stress.

Dervishi et al. (2018) analysed blood metabolites on a small sample of the pigs studied by Camerlink, Reimerts and co-workers. At an age of 22 weeks, high-social pigs had lower concentration of serotonin and lower ratio of tryptophan/kynurenine (tryptophan is the precursor of serotonin) which might indicate less aggression. They also had lower concentration of epinephrine and higher concentration of phenyl-ethylamine which might indicate a lower activity of the sympathetic-adrenal-medullary system and thus less stressed animals (Dervishi et al., 2018).

In a genome-wide association study, the average growth rate of unrelated pen mates was used as the phenotype (Hong et al., 2018b). The heritability for this trait was estimated at 0.14 . Around 1000 Landrace pigs were genotyped 
and 5 SNPs, all on chromosome 6, were detected. The authors point out that one of these markers is located upstream of the gene interferon-induced protein 44 (IF144); a gene known to influence stress-induced diseases in humans. This fits well with Reimert's (2014) conclusion that pigs with high social genetic breeding values for growth rate "may indeed be pigs that are less easily stressed". Wu et al. (2019) estimated direct and social breeding values for growth rate and performed a whole-genome re-sequencing association study for these effects in Large White pigs. They detected 151 SNPs, pointing to 42 candidate genes, for the direct breeding values and 205 SNPs, pointing to 54 candidate genes, for the social breeding values. One of the candidate genes for both direct and social effects is a protein coding gene called GABRR2. Wu et al. (2019) refer to several studies showing that this gene is involved in behavioural stress response as well as aggressiveness in animals.

Based on social breeding values for growth rate in performance test, gilts were sorted into two groups; one with high and one with low social breeding values (Hong et al., 2017). The gilts (in total 124 animals) were thereafterfollowed for several parities. Gilts with high social breeding values were younger at first farrowing. As sows, they gave birth to larger litters and had shorter weaning to oestrous intervals (Hong et al., 2017).

In summary, all studies on social genetic effects together show that the social genetic model has the potential to improve animal welfare, but the background of social interactions among pigs is complex. The 'best' model also seems to differ between populations (Kim et al., 2016). Some breeding companies already estimate direct and social genetic breeding values for growth rate and apply them in thegenetic evaluation, expecting benefit in reduced damaging behaviour (Egbert Knol, personal communication). There are, however, still questions regarding the optimum weight of behavioural traits in the breeding goal.

\section{Conclusion and future trends}

Most behavioural traits seem to be governed by many genes, each with a rather small but additive effect on the phenotype. Therefore, marker-assisted selection (MAS) seems less promising today than when the method was introduced in the 1980s. Selection for changed behaviour based on best linear unbiased prediction (BLUP) breeding values is probably a better alternative than MAS for most traits. With genomic BLUP breeding values (based on a combination of data from SNP markers from all pigs and phenotypic data from pigs in a reference population) breeding values can be estimated with higher accuracies than traditional BLUP values. Expressed in another way, less phenotype records are needed for estimating G-BLUP values with a certain accuracy as compared to ordinary BLUP values. Genomic selection is especially relevant for traits that 
are complicated and expensive to record, which is true for many behavioural traits. In genomic selection, knowledge about markers from genome-wide association studies like the ones previously mentioned in this chapter can improve the accuracy of genetic evaluation of behavioural traits even further. Also the accuracy of direct and social breeding values for growth rate can be improved by genomic selection (Hong et al., 2019). Genomic selection on social genetic effects however requires genotyping of almost all pigs in the pen, as discussed by Duijvesteijn (2014). This may not be done today, but could become affordable with a decreasing genotyping price.

New methods for gene editing are rapidly developing and opportunities for animal breeding are discussed (Van Eenennaam, 2017). Given the complex genetic and physiological background of behavioural traits, it seems unlikely that gene editing will be used to change the behaviour of pigs in future breeding programs. Nevertheless, gene editing may have indirect consequences on behavioural traits. Assume, for example, that boar taint can be reduced by gene editing. Then all male pigs could be reared as entire males instead of castrates. Assume also that gene editing changes the metabolism of androstenone (a pheromone causing off-flavour in pork) without influencing the level of testosterone and other hormones. That means the gene-edited pigs would show as much aggressive behaviour as today's entire males. In such a scenario, the motives for selection against aggressive behaviour (based on breeding values) would be even stronger than today.

In this chapter, genetic studies of allele effects have been reviewed from a molecular and from a quantitative genetic angle. A possible future of animal production may be to use epigenetic effects to influence gene expression. Epigenetic effects influence the phenotype by regulation of gene expression rather than alterations in the DNA sequence. Assume epigenetic effects on genes involved in aggressive behaviour can be transmitted from generation to generation as reviewed by David et al. (2019). Further assume that a good treatment of parents early in life influences DNA methylation of their offspring in such a way that alleles associated with aggressive behaviour are turned off. Then providing young Al-boar candidates in sire lines with the very best environment (enriched environment, tailor-made feed, etc.) could make a huge difference for the welfare of all pigs raised for slaughter. The number of these young boars is low (since they can be selected with a high accuracy based on genomic breeding values early in life) and thus it would be affordable to give them an enriched, more expensive environment.

It is known from several studies that gut microbiota influences social behaviour (reviewed by Sherwin et al., 2019) and the genotype of the pig influences the establishment of the microbiota (Camarinha-Silva et al., 2017). The relationships between microbiota, immune system and stress reactivity may play a role in the development of tail biting. In the synthesis article of 
Brunberg et al. (2016) we discussed the possibility that tail biting pigs have a different composition of gut microbiota than pigs that do not show tail biting. If yes, is the microbiota simply transferred from the sow to its piglets? Or is being a good host for good microbiota a heritable trait? That would open up for a future possibility to select pigs with favourable microbiota, in order to decrease tail biting.

The development of the group model is still ongoing. Canario et al. (2017) showed that non-genetic social factors on growth rate are larger than genetic social factors. Piglets sharing the same environment early in life develop common social skills that generate early-life social effects (ELSEs). These ELSEs can have a strong influence on the penmates later in life. Canario et al. (2017) estimated both genetic social effects and ELSEs and showed that including ELSEs reduces bias when estimating social genetic breeding values.

Until now, the group model has mostly been used for analysing performance traits. It can, however, also be used for behavioural traits such as tail-biting (Canario and Flatres-Grall, 2018) or traits that are indicators of aggressive behaviour, such as skin lesions. Angarita et al. (2019) analysed skin lesions of 792 growing pigs in 59 pens with the group model. Aggressive behaviour within each dyad was recorded at the day of mixing. The skin lesions were counted on the following day. An ordinary group model assuming uniform interactions between dyads was compared to an intensity-based group model. Both models included the total time in aggressive interactions per pig. The intensity-based group model including unilateral attack behaviour resulted in higher heritability estimates for lesion scores. The correlations were positive for all lesion scores. Angarita et al. (2019) conclude that if behavioural observations are available, selection incorporating social genetic effects "may reduce the consequences [i.e. the skin lesions] of aggressive behaviours after mixing pigs".

The number of phenotype records is still a severe limitation when performing genetic studies of behavioural traits. Rodenburg et al. (2019) argue that a combined sensor and genomics approach can facilitate genetic studies of behavioural traits. Image-based recording methods, and sensors keeping track of individuals in a group, pave the way for new selection traits. The breeding goal can be either the behaviour itself, or the behaviour can be used as an indicator for a goal trait like robustness, for example, drinking behaviour during heat waves.

It would be interesting to study the neutral pigs, not involved in tail biting or aggressive interactions, more in depth. Can breeding values be estimated for the ability to stay neutral? How is this ability correlated to other traits, like feeding behaviour and calmness? Rauw et al. (2017) state, "Although it is generally proposed that animal welfare improves with selection for calmer animals that are less fearful and reactive to novelty, animals bred to be less sensitive with fewer desires may be undesirable from an ethical point of view." 
As for other ethical questions, different persons may have different views on selection for less responsive pigs.

Selection against tail biting and aggressive behaviour seems possible and yet it is not common. More studies can always be asked for, for example, further studies of potential side effects of selection against aggressive behaviour based on behavioural observations or skin lesions. What would, for example, be the consequences for the care takers? König von Borstel et al. (2018) reported that skin lesions after mixing has a negative genetic correlation with agitation at weighing (less lesions - more agitated pigs) whereas D'Eath et al. (2009) reported that aggressive behaviour at mixing has a positive genetic correlation with activity during weighing (more aggressive - more activity). Both very agitated pigs and very non-active pigs may lead to more work for the care takers.

Peden et al. (2018) ask why "in spite of the amount of research on reducing aggression at mixing the problem has not reduced in intensive farming systems". They conclude that the industry seems to give low priority to the problem and recommend "a better alignment between research questions and industry interests to increase the success of research efforts to improve animal welfare in practice." Research results may also influence the industry indirectly, as a base for animal welfare laws. Changes in legislation can, potentially, change the economic weights given to different traits in the breeding goal. Tail docking has become forbidden in EU, and that should increase breeding organisations' interest in selection against tail biting. So far, legal consequences of tail docking are, however, negligible in many countries and neither breeding goals nor management routines seem to change. Value shifts in society, leading to consumers not accepting certain management routines, may become a future driver for changed breeding goals. Although many questions are unsolved, there is knowledge already available that can be implemented by breeding organisations ready for change.

\section{Where to look for further information}

Many doctoral theses include a general discussion that is easy to read and full of valuable information and interesting ideas. These texts are missed when only looking for articles published in scientific journals. I especially recommend the theses by Camerlink, Reimert, Duijvesteijn and Ursinus, all from Wageningen University, 2014. Some key researchers in genetics of pig behaviour are Laurianne Canario (INRA, France), Pieter Bijma (Wageningen University, The Netherlands) and Simon Turner (SRUC, UK) who have a long history of fruitful cooperation. The yearly conference of the European Federation for Animal Science (EAAP) gives good opportunities for meeting geneticists interested in animal behaviour. 


\section{Personal communications}

Dr. Egbert Knol, Topigs Norsvin Research Center B.V., Beuningen, The Netherlands; 2019-11-11.

Dr. Hubert Henne, BHZP GmbH, Dahlenburg - Ellringen, Germany. 2019-11-14.

\section{References}

Angarita, B. K., Cantet, R. J. C., Wurtz, K. E., O'Malley, C. I. O., Siegford, J. M., Ernst, C. W., Turner, S. P. and Steibel, J. P. (2019). Estimation of indirect social genetic effects for skin lesion count in group-housed pigs by quantifying behavioral interactions. J. Anim. Sci. 97(9), 3658-3668.

Appel, A. K., Voß, B., Tönepöhl, B., König von Borstel, U. and Gauly, M. (2013). Variance components of aggressive behavior in genetically highly connected Pietrain populations kept under two different housing conditions. J. Anim. Sci. 91(12), 5557-5564.

Appel, A. K., Voß, B., Tönepöhl, B., König von Borstel, U., Gauly, M. (2016). Genetic associations between maternal traits and aggressive behaviour in Large White sows. Animal 10(7), 1234-1242.

Bauer, J. (2019). Investigation of the genetic components of maternal infanticide in Sus Scrofa. Doctoral thesis, University of Cambridge, UK. https://doi.org/10.17863/CAM .40257.

Baxter, E. M., Jarvis, S., Sherwood, L., Farish, M., Roehe, R., Lawrence, A. B. and Edwards, S. A. (2011). Genetic and environmental effects on piglet survival and maternal behaviour of the farrowing sow. Appl. Anim. Behav. Sci. 130(1-2), 28-41.

Bergsma, R., Kanis, E., Knol, E. F. and Bijma, P. (2008). The contribution of social effects to heritable variation in finishing traits of domestic pigs (Sus scrofa). Genetics 178(3), 1559-1570.

Bijma, P., Muir, W. M. and Van Arendonk, J. A. M. (2007). Multilevel selection 1: quantitative genetics of inheritance and response to selection. Genetics 175(1), 277-288.

Bijma, P. (2010a). Multilevel selection 4: modeling the relationship of indirect genetic effects and group size. Genetics 186(3), 1029-1031.

Bijma, P. (2010b). Estimating indirect genetic effects: precision of estimates and optimum designs. Genetics 186(3), 1013-1028.

Breuer, K., Sutcliffe, M. E. M., Mercer, J. T., Rance, K. A., Beattie, V. E., Sneddon, I. A. and Edwards, S. E. (2005). The effect of breed on the development of adverse social behaviours in pigs. Appl. Anim. Beh. Sci. 84, 59-74.

Brunberg, E., Jensen, P., Isaksson, A. and Keeling, L. J. (2013a). Behavioural and brain gene expression profiling in pigs during tail biting outbreaks - Evidence of a tail biting resistant phenotype. PLoS ONE 8(6), e66513.

Brunberg, E., Jensen, P., Isaksson, A. and Keeling, L. J. (2013b). Brain gene expression differences are associated with abnormal tail biting behavior in pigs. Genes Brain Behav. 12(2), 275-281.

Brunberg, E. I., Rodenburg, T. B., Rydhmer, L., Kjaer, J. B., Jensen, P. and Keeling, L. J. (2016). Omnivores going astray: a review and new synthesis of abnormal behavior in pigs and laying hens. Front. Vet. Sci. 3, 57. 
Bunter, K. L., Lewis, C. R. and Newman, S. (2015). Social genetic effects influence reproductive performance of group-housed sows. J. Anim. Sci. 93(8), 3783-3793.

Camarinha-Silva, A., Maushammer, M., Wellmann, R., Vital, M., Preuss, S. and Bennewitz, J. (2017). Host genome influence on gut microbial composition and microbial prediction of complex traits in pigs. Genetics 206(3), 1637-1644.

Camerlink, I., Turner, S. P., Bijma, P. and Bolhuis, J. E. (2013). Indirect genetic effects and housing conditions in relation to aggressive behaviour in pigs. PLOS ONE 8(6), e65136.

Camerlink, I. (2014). Sociable swine: indirect genetic effects on growth rate and their effect on behaviour and production of pigs in different environments. PhD thesis, Wageningen University, the Netherlands.

Camerlink, I., Ursinus, W. W., Bijma, P., Kemp, B. and Bolhuis, J. E. (2015). Indirect genetic effects for growth rate in domestic pigs alter aggressive and manipulative biting behaviour. Behav. Genet. 45(1), 117-126.

Canario, L., Turner, S. P., Roehe, R., Lundeheim, N., D'Eath, R. B., Lawrence, A. B., Knol, E., Bergsma, R. and Rydhmer, L. (2012). Genetic associations between behavioral traits and direct-social effects of growth rate in pigs. J. Anim. Sci. 90(13), 4706-4715.

Canario, L., Lundeheim, N. and Bijma, P. (2017). The early-life environment of a pig shapes the phenotypes of its social partners in adulthood. Heredity 118(6), 534-541.

Canario, L. and Flatres-Grall, L. (2018). Genetics of tail-biting receipt in gilts from the Tai Zumu line. Proc. World Congress Genetics Applied to Livest. Prod. (WCGALP) 11, 572.

Chen, C., Gilbert, C. L., Yang, G., Guo, Y., Segonds-Pichon, A., Ma, J., Evans, G., Brenig, B., Sargent, C., Affara, N. and Huang, L. (2008). Maternal infanticide in sows: incidence and behavioural comparisons between savaging and non-savaging sows at parturition. Appl. Anim. Beh. Sci. 109(2-4), 238-248.

Chen, C. Y., Johnson, R. K., Newman, S., Kachman, S. D. and van Vleck, L. D. (2009a). Effects of social interactions on empirical responses to selection for average daily gain of boars. J. Anim. Sci. 87(3), 844-849.

Chen, C., Guo, Y., Yang, G., Yang, Z., Zhang, Z., Yang, B., Yan, X., Perez-Enciso, M., Ma, J., Duan, Y., Brenig, B. and Huang, L. (2009b). A genome wide detection of quantitative trait loci on pig maternal infanticide behavior in a large scale White Duroc x Erhualian resource population. Behav. Genet. 39(2), 213-219.

Colpoys, J. D., Abell, C. E., Young, J. M., Keating, A. F., Gabler, N. K., Millman, S. T., Siegford, J. M. and Johnson, A. K. (2014). Effects of genetic selection for residual feed intake on behavioral reactivity of castrated male pigs to novel stimuli tests. Appl. Anim. Beh. Sci. 159, 34-40.

Cross, A. J., Keel, B. N., Brown-Brandl, T. M., Cassady, J. P. and Rohrer, G. A. (2018). Genome-wide association of changes in swine feeding behaviour due to heat stress. Genet. Sel. Evol. 50(1), article number 11.

Daigle, C. (2018). Parallels between postpartum disorders in humans and preweaning piglet mortality in sows. Animals 8(2), 22 (11 pp).

David, I., Canario, L., Combes, S. and Demars, J. (2019). Intergenerational transmission of characters through genetics, epigenetics, microbiota, and learning in livestock. Front. Genet. 10, 1058.

D'Eath, R. B., Roehe, R., Turner, S. P., Ison, S. H., Farish, M., Jack, M. C. and Lawrence, A. B. (2009). Genetics of animal temperament: aggressive behaviour at mixing 
is genetically associated with the response to handling in pigs. Animal 3(11), 1544-1554.

Dervishi, E., Zande, L., Reimert, I., Pramod, M. K., Knol, E. F. and Plastow, G. S. (2018). A pilot study to investigate the relationship between social behavior and serum metabolite concentration in finisher pigs. J. Anim. Sci. 96, Issue supplement 3. - ISSN 0021-8812 - p. 12 - 12

Dervishi, E., van der Zande, L., Valente, S. T. da, Reimert, I., Pramod, M. K., Knol, E. F., Plastow, G. S. and Lopes, M. S. (2019). Combining metabolomics and genomics to elucidate physiological processes related to tail damage score in pigs. In: Proceedings of the 37th International Society for Animal Genetics Conference (ISAG), pp. 147-147.

Desire, S., Turner, S. P., D'Eath, R. B., Doeschl-Wilson, A. B., Lewis, C. R. G. and Roehe, R. (2015). Genetic associations of short- and long-term aggressiveness identified by skin lesions with growth, feed efficiency, and carcass characteristics in growing pigs. J. Anim. Sci. 93(7), 3303-3312.

Desire, S., Turner, S. P., D'Eath, R. B., Doeschl-Wilson, A. B., Lewis, C. R. and Roehe, R. (2016). Prediction of reduction in aggressive behaviour of growing pigs using skin lesion traits as selection criteria. Animal 10(8), 1243-1253.

Ding, R., Quan, J., Yang, M., Wang, X., Zheng, E., Yang, H., Fu, D., Yang, Y., Yang, L., Li, Z., Liu, D., Cai, G., Wu, Z. and Yang, J. (2017). Genome-wide association analysis reveals genetic loci and candidate genes for feeding behavior and eating efficiency in Duroc boars. PLoS ONE 12(8), e0183244.

Duijvesteijn, N. (2014). Sociable Swine: prospects of indirect genetic effects for the improvement of productivity, welfare and quality. PhD thesis, Wageningen University, the Netherlands.

Gäde, S., Bennewitz, J., Kirchner, K., Looft, H., Knap, P. W., Thaller, G. and Kalm, E. (2008). Genetic parameters for maternal behaviour traits in sows. Livest. Sci. 114(1), 31-41.

Gilbert, C. L. (2001). Endocrine regulation of periparturient behaviour in pigs. Reprod. Suppl. 58, 263-266.

Gley, K., Murani, E., Trakooljul, N., Zebunke, M., Puppe, B., Wimmers, K. and Ponsuksili, S. (2019). Transcriptome profiles of hypothalamus and adrenal gland linked to haplotype related to coping behavior in pigs. Sci. Rep. 9(1), article number 13038.

Grandinson, K., Lund, M. S., Rydhmer, L. and Strandberg, E. (2002). Genetic parameters for the piglet mortality traits crushing, stillbirth and total mortality, and their relation to birth weight. Acta Agric. Scand. A 52(4), 167-173.

Guo, Y. M., Zhang, Z. Y., Ma, J. W., Ai, H. S., Ren, J. and Huang, L. S. (2015). A genomewide association study of feed efficiency and feeding behaviors at two fattening stages in a White Duroc $\times$ Erhualian F population. J. Anim. Sci. 93(4), 1481-1489.

Hellbrügge, B., Tölle, K.-H., Henze, C., Presuhn, U., and Krieter, J. (2007). A note on genetic parameters for human-approach tests on gilts. In: Genetic Aspects of Piglet Losses and the Maternal Behaviour of Sows. Schriftenreihe Des Instituts Fur Tierzücht und Tierhaltung Der Christian-Albrechts-Universität zu Kiel, Heft, 158.

Hellbrügge, B., Tölle, K. H., Bennewitz, J., Henze, C., Presuhn, U. and Krieter, J. (2008). Genetic aspects regarding piglet losses and the maternal behaviour of sows, Part 2. Genetic relationship between maternal behaviour in sows and piglet mortality. Animal 2(9), 1281-1288.

Hong, J. K., Kim, Y. M., Cho, K. H., Park, J. C. and Lee, D. H. (2017). Reproductive performance of sows selected for divergent social genetic effects for growth. Anim. Reprod. 14(Sup. 1), 1292-1297. 
Hong, J. K., Kim, K. H.,Song, N. R., Choi, T., Hwang, H. S., Lee, J. K., Eom, T. K. and Rhim, S. J. (2018a). Social behavior and group growth of finishing pigs with divergent social breeding values. Rev. Colom Cienc. Pecua 31(4), 267-275.

Hong, J. K., Jeong, Y. D., Cho, E. S., Choi, T. J., Kim, Y. M., Cho, K. H., Lee, J. B., Lim, H. T. and Lee, D. H. (2018b). A genome-wide association study of social genetic effects in Landrace pigs. Asian-Australas. J. Anim. Sci. 31(6), 784-790.

Hong, J. K., Kim, Y. S., Cho, K. H., Lee, D. H., Min, Y. J.and Cho, E. S. (2019). Application of single-step genomic evaluation using social genetic effect model for growth in pig. Asian-Australas. J. Anim. Sci. 32(12), 1836-1843.

Jarvis, S., Reed, B. T., Lawrence, A. B., Calvert, S. K. and Stevenson, J. (2004). Peri-natal environmental effects on maternal behaviour, pituitary and adrenal activation, and the progress of parturition in the primiparous sow. Anim. Welf. 13(2), 171-181.

Jonas, E. and Rydhmer, L. (2018). Effect of candidate genes for maternal ability on piglet survival and growth. Livest. Sci. 207, 83-90.

Kavlak, A. T. and Uimari, P. (2019). Estimation of heritability of feeding behaviour traits and their correlation with production traits in Finnish Yorkshire pigs. J. Anim. Breed. Genet. 136(6), 484-494.

Kim, Y. M., Cho, E. S., Cho, K. H., Sa, S. J., Jeong, Y. D., Woo, J. S., Lee, I. J. and Hong, J. K. (2016). Social genetic effects on days to $90 \mathrm{~kg}$ in Duroc and Yorkshire pigs. Korean. J. Agr. Sci. 43(4), 595-602.

König von Borstel, U., Tönepöhl, B., Appel, A. K., Voß, B., Brandt, H., Naderi, S. and Gauly, M. (2018). Suitability of traits related to aggression and handleability for integration into pig breeding programmes: genetic parameters and comparison between Gaussian and binary trait specifications. PLoS ONE 13(12), 17 pp.

Koolhaas, J. M. and Boer, S. F. (2008). Coping styles and aggression: a biobehavioral approach. In: Vingerhoets, A. J. J. M., Nyklíček, I. and Denollet, J. (Eds), Emotion Regulation: Conceptual and Clinical Issues. Springer, Boston, US, pp. 12-26.

Lan, J., Lei, M. G., Zhang, Y. B., Wang, J. H., Feng, X. T., Xu, D. Q., Gui, J. F. and Xiong, Y. Z. (2009). Characterization of the porcine differentially expressed PDK4 gene and association with meat quality. Mol. Biol. Rep. 36(7), 2003-2010.

Løvendahl, P., Damgaard, L. H., Nielsen, B. L., Thodberg, K., Su, G. and Rydhmer, L. (2005). Aggressive behaviour of sows at mixing and maternal behaviour are heritable and genetically correlated traits. Livest. Prod. Sci. 93(1), 73-85.

Meunier-Salaün, M. C., Guérin, C., Billon, Y., Sellier, P., Noblet, J. and Gilbert, H. (2014). Divergent selection for residual feed intake in group-housed growing pigs: characteristics of physical and behavioural activity according to line and sex. Animal 8(11), 1898-1906.

Muir, W. M. (2005). Incorporation of competitive effects in forest tree or animal breeding programs. Genetics 170(3), 1247-1259.

Nielsen, H. M., Ask, B. and Madsen, P. (2018). Social genetic effects for growth in pigs differ between boars and gilts. Genet. Sel. Evol. 50(1), 4.

Ocepek, M., Rosvold, E. M., Andersen-Ranberg, I. and Andersen, I. L. (2017). Can we improve maternal care in sows? Maternal behavioral traits important for piglet survival in loose-housed sow herds. J. Anim. Sci. 95(11), 4708-4717.

Ocepek, M. and Andersen, I. L. (2018). Sow communication with piglets while being active is a good predictor of maternal skills, piglet survival and litter quality in three different breeds of domestic pigs (Sus scrofa domesticus). PLoS ONE 13(11), e0206128. 
Peden, R. S. E., Turner, S. P., Boyle, L. A. and Camerlink, I. (2018). The translation of animal welfare research into practice: the case of mixing aggression between pigs. Appl. Anim. Beh. Sci. 204, 1-9.

Ponsuksili, S., Zebunke, M., Murani, E., Trakooljul, N., Krieter, J., Puppe, B., Schwerin, M. and Wimmers, K. (2015). Integrated Genome-wide association and hypothalamus eQTL studies indicate a link between the circadian rhythm-related gene PER1 and coping behavioral. Sci. Rep. 5, 16264.

Rauw, W. M., Johnson, A. K., Gomez-Raya, L. and Dekkers, J. C. M. (2017). A hypothesis and review of the relationship between selection for improved production efficiency, coping behavior, and domestication. Front. Genet. 8, 134.

Reimert, I., Rodenburg, T. B., Ursinus, W. W., Duijvesteijn, N., Camerlink, I., Kemp, B. and Bolhuis, J. E. (2013). Backtest and novelty behavior of female and castrated male piglets, with diverging social breeding values for growth. J. Anim. Sci. 91(10), 4589-4597.

Reimert, I. (2014). (Em)pathetic pigs?: the impact of social interactions on welfare, health and productivity. PhD thesis, Wageningen University, the Netherlands.

Reimert, I., Rodenburg, T. B., Ursinus, W. W., Kemp, B. and Bolhuis, J. E. (2014a). Responses to novel situations of female and castrated male pigs with divergent social breeding values and different backtest classifications in barren and straw-enriched housing. Appl. Anim. Behav. Sci. 151, 24-35.

Reimert, I., Rodenburg, T. B., Ursinus, W. W., Kemp, B. and Bolhuis, J. E. (2014b). Selection based on indirect genetic effects for growth, environmental enrichment and coping style affect the immune status of pigs. PLoS ONE 9(9), e108700.

Reyer, H., Shirali, M., Ponsuksili, S., Murani, E., Varley, P. F., Jensen, J. and Wimmers, K. (2017). Exploring the genetics of feed efficiency and feeding behaviour traits in a pig line highly selected for performance characteristics. Mol. Genet. Genomics 292(5), 1001-1011.

Rodenburg, T. B., Bijma, P., Ellen, E. D., Bergsma, R., de Vries, S., Bolhuis, J. E., Kemp, B. and van Arendonk, J. A. M. (2010). Breeding amiable animals? Improving farm animal welfare by including social effects in breeding programmes. Anim. Welf. 19(S), 77-82.

Rodenburg, T. B., Van Der Zande, L., De Haas, E. N., Koštál, L., Pichová, K., Piette, D., Tetens, J., Visser, B., DeKlerk, B., Van Der Sluis, M., Bennewitz, J., Siegford, J., Norton, T., Guzhva, O. and Ellen, E. E. (2019). Reduce damaging behaviour in laying hens and pigs by developing sensor technologies to inform breeding programs. In: Newberry, R. C. and Braastad, B. O. (Eds), Animal Lives Worth Living Proceedings 53rd Congress of the International Society for Applied Ethology, Norway.

Rohrer, G. A., Brown-Brandl, T., Rempel, L. A., Schneider, J. F. and Holl, J. (2013). Genetic analysis of behavior traits in swine production. Livest. Sci. 157(1), 28-37.

Rydhmer, L. and Jonas, E. (2016). Oxytocin candidate genes and maternal behaviour of sows. Proceedings of the 67th Meeting of the European Federation of Animal Science, UK. Session 60, p. 529.

Sheffler, K., Stamer, E., Traulsen, I. and Krieter, J. (2016). Estimation of genetic parameters for agonistic behaviour of pigs at different ages. J. Agric. Sci. 154, 732-741.

Sherwin, E., Bordenstein, S. R., Quinn, J. L., Dinan, T. G. and Cryan, J. F. (2019). Microbiota and the social brain. Science 366(6465).

Stratz, P., Just, A., Faber, H. and Bennewitz, J. (2016). Genetic analyses of mothering ability in sows using field-recorded observations. Livest. Sci. 191, 1-5. 
Stukenborg, A., Traulsen, I., Stamer, E., Puppe, B., Presuhn, U. and Krieter, J. (2012). Heritabilities of agonistic behavioural traits in pigs and their relationships within and between different age groups. Livest. Sci. 149(1-2), 25-32.

Terenina, E., Bazovkina, D., Rousseau, S., Salin, F., D'Eath, R., Turner, S., Kulikov, A. and Mormède, P. (2012). Association entre polymorphisms de genes candidats et comportements agressifs chez le porc. J. Rech. Porcine Fr. 44, 45-46.

Turner, S. P., Roehe, R., D'Eath, R. B., Ison, S. H., Farish, M., Jack, M. C., Lundeheim, N., Rydhmer, L. and Lawrence, A. B. (2009). Genetic validation of postmixing skin injuries in pigs as an indicator of aggressiveness and the relationship with injuries under more stable social conditions. J. Anim. Sci. 87(10), 3076-3082.

Ursinus, W. (2014). A tale too long for a tail too short? Identification of characteristics in pigs related to tail biting and other oral manipulations directed at conspecifics. PhD thesis, Wageningen University, the Netherlands.

Ursinus, W. W., Van Reenen, C. G., Kemp, B. and Bolhuis, J. E. (2014). Tail biting behaviour and tail damage in pigs and the relationship with general behaviour: predicting the inevitable? Appl. Anim. Beh. Sci. 156, 22-36.

Van Eenennaam, A. L. (2017). Genetic modification of food animals. Curr. Opin. Biotechnol. 44, 27-34.

Vangen, O., Holm, B., Valros, A., Lund, M. S. and Rydhmer, L. (2005). Genetic variation in sows' maternal behaviour, recorded under field conditions. Livest. Prod. Sci. 93(1), 63-71.

Wallenbeck, A. and Keeling, L. J. (2013). Using data from electronic feeders on visit frequency and feed consumption to indicate tail biting outbreaks in commercial pig production. J. Anim. Sci. 91(6), 2879-2884.

Wilson, K., Zanella, R., Ventura, C., Johansen, H. L., Framstad, T., Janczak, A., Zanella, A. J. and Neibergs, H. L. (2012). Identification of chromosomal locations associated with tail biting and being a victim of tail-biting behaviour in the domestic pig (Sus scrofa domesticus). J. Appl. Genet. 53(4), 449-456.

Wu, P., Wang, K., Yang, Q., Zhou, J., Chen, D., Liu, Y.,Ma, J., Tang, Q., Jin, L., Xiao, W., Lou, P., Jiang, A., Jiang, Y., Zhu, L., Li, M., Li, X. and Tang, G. (2019). Whole-genome re-sequencing association study for direct genetic effects and social genetic effects of six growth traits in Large White pigs. Scientific Reports 9, article number 9667.

Wurtz, K. E., Siegford, J. M., Bates, R. O., Ernst, C. W. and Steibel, J. P. (2017). Estimation of genetic parameters for lesion scores and growth traits in group-housed pigs. J. Anim. Sci. 95(10), 4310-4317.

Zebunke, M., Nurnberg, G., Melzer, N. and Puppe, B. (2017). The backtest in pigs revisitedinter-situational behaviour and animal classification. Appl. Anim. Beh. Sci. 194, 7-13. 
